\title{
PSP/reg: a potent and enigmatic trophic factor, which is upregulated during the pathogenesis of diabetes
}

\author{
Caroline Bonner
}

Received: 21 November 2014 / Accepted: 1 December 2014/Published online: 11 December 2014

(C) Springer Science+Business Media New York 2014

Pancreatic islet dysfunction and death, which are key characteristics of type 1 diabetes mellitus (T1DM), are now befalling also in the pathogenesis of type 2 diabetes mellitus (T2DM). Prospective studies of high-risk patients or newly diagnosed with T2DM imply that disease progression correlates with a relatively modest deterioration of insulin resistance, followed by a steep decline in residual beta cell function $[1,2]$, while others argue that a decrease in beta cell mass is the key contributor to the progression of T2DM [3]. It is indeed plausible to consider, that both scenarios, loss of function and loss of mass, are at work in T2DM [4]. With respect to the latter, a decrease in beta cell mass may be caused by defects in beta cell differentiation and proliferation, a decrease in beta cell size, or an increased rate of beta cell apoptosis [3, 5]. It is important to emphasize, however, that a decrease in beta cell mass does not necessarily suggest that new beta cells are not generated during disease progression. In fact, Dor and colleagues argue that beta cell mass is not static but in a constant process of cell death and renewal [6]. Conversely, Talchai et al., argue that beta cells do not undergo apoptosis, but instead cheat cell death by dedifferentiating into alpha-like cells [7]. Although it is apparent that beta cell mass regeneration does occur, it is not clear whether this happens through self-renewal of mature beta cells or through neogenesis of progenitor cells residing in the pancreas or recruited from other near-by tissues such as the liver [8].

C. Bonner $(\bowtie)$

European Genomic Institute for Diabetes (EGID), FR 3508, 59000 Lille Cedex, France

e-mail: caroline.bonner@univ-lille2.fr

C. Bonner

U859 INSERM Biothérapies du Diabète, Faculté de Médecine

3EST, 1, Place de Verdun, 59045 Lille Cedex, France
PSP/reg (regenerating protein) belongs to the Regenerating family of proteins [9]. However, regenerating gene 1 (Reg 1) and pancreatic stone protein (PSP) have been discovered independently in the fields of diabetes and pancreatitis [10]. Sequence analysis later revealed that Regl and PSP are indeed identical [11], and for clarification purposes Graf and colleagues suggested that the combined terms of PSP/reg to be used in the future [10]. $\mathrm{PSP} / \mathrm{reg}$ has been shown to be physiologically secreted from rat pancreatic acinar cells [12], but it's also expressed in human non-beta islet cells [13] and in the liver [14]. Its regenerative capabilities were first identified in an unbiased screening study of genes involved in beta cell regeneration [9]. Additionally, PSP/reg has been shown to increase beta cell mass and to stimulate beta cell proliferation under physiological conditions and in rodent models of diabetes $[9,10]$. A more recent study has shown that apoptotic beta cells secrete factor(s) that can stimulate $P S P / r e g$ gene induction in neighboring islet cells, which in turn are able to facilitate islet/beta cell regeneration [15]. Of note, these observations were observed in rodents, which unlike humans, have a small percentage of alpha and delta cells compared to beta (80-90\% beta) [16]. Collectively, these findings led to the conclusions that PSP/reg may be a protein involved in neogenesis and regeneration $[10,11]$ and may act as a growth mediator stimulating the proliferation of beta cells $[9,10]$. Evidently, activation of $P S P /$ reg gene is thought to be an important event in islet cell regeneration and diabetogenesis. However, the mechanisms involved remain largely unknown, and more importantly, whether the "regenerating" neighboring islets cells are of alpha, beta, or delta origin remains an enigma.

In this issue of Endocrine, Yang and colleagues describe the prognostic value of $\mathrm{PSP} / \mathrm{reg}$ serum concentration in patients at different clinical stages of T2DM as well as 
long-term diabetic patients with secondary complications [17]. They enrolled 1121 participants (479 males, 642 females; age range 23-80 years). The authors demonstrated that PSP/reg serum levels were elevated in highrisk and impaired glucose regulation (IGR) patients $(p<0.05)$, but PSP/reg levels were much higher in newly diagnosed T2DM patients $(p<0.001)$ and long-term diabetic patients with secondary complications $(p<0.001)$. They also show that PSP/reg secretion correlates strongly with duration of diabetes, HbA1c, pulse pressure and smoking, but not with age, gender, or BMI. The authors conclude that PSP/reg might be a useful predictor of T2DM disease progression. The data presented in the article are solid, and the finding that PSP/reg is significantly induced in a large cohort of human subjects with various degrees of insulin resistance is novel and of great interest to the field, but several intriguing questions remain unanswered: Is PSP/reg expression/upregulation related to beta cell injury or to beta cell dedifferentiation (an early mechanism that underlies the pathogenesis of T2DM) [7]? In which islet cell subtype(s) is PSP/reg expressed during the pathogenesis of T2DM (alpha, beta, or delta)? Is a single PSP/reg measurement in the absence of other islet hormones such as insulin and glucagon (which are known to be perturbed in T2DM) sufficient to predict disease progression?

It's important to note that previous studies by Bacon and colleagues have shown that PSP/reg serum levels were also significantly elevated in HNF1A-MODY patients compared to normoglycemic subjects [18]. Similar to the findings of Yang and colleagues [17], they also noted that $\mathrm{PSP} / \mathrm{reg}$ serum levels correlated with age $(>25$ years of age) [18]. However, the same authors reported that PSP/reg serum levels were also elevated in T1DM patients compared to controls [15, 18], but in these subjects, PSP/reg serum levels did not correlate with duration of diabetes [18]. Indeed, the study by Yang and colleagues added new and important data on the time-dependent increase of PSP/ reg levels in subjects with T2DM that may signal an important risk factor for its complications [17]. However, there is a long way to go before PSP/reg alone can be considered as a potential biomarker for T2DM in the clinic, since it is not sufficient to discriminate patients with T1DM, T2DM, or HNF1A-MODY.

Recent studies suggest that circulating, non-neural, noncell autonomous factors secreted from key metabolic tissues such as the liver contribute to link insulin resistance in the presence or absence of diabetes to beta cell functional mass $[19,20]$. However, the precise physiological mechanisms responsible for this fate are currently unknown. Since, PSP/reg gene is inducible by hyperglycemia and secreted [15], it is enticing to hypothesize that its gene product may function as a mitogenic, trophic and/or an antiapoptotic factor in the endocrine pancreas. We can also only hypothesize whether the source of PSP/reg in the serum of T2DM patients was the endocrine or exocrine pancreas, i.e., alpha, beta, or delta cells or acinar cells, since protein localization studies do not currently exist in human pancreatic sections. We can equally not exclude that these levels came from other organs potentially affected in T2DM such as the liver where PSP/reg is also expressed [10], and that a crosstalk between liver and pancreatic dysfunction occurs. The future use of PSP/reg as a rapid predictor of $\mathrm{T} 2 \mathrm{D}$ and disease progression is an enticing prospect; however, these initial results should be tempered as we await confirmatory molecular data for the specific localization and function of PSP/reg in human T2DM pancreatic islets.

Disclosures The author has nothing to disclose.

\section{References}

1. C. Weyer, C. Bogardus, D.M. Mott, R.E. Pratley, The natural history of insulin secretory dysfunction and insulin resistance in the pathogenesis of type 2 diabetes mellitus. J. Clin. Investig. 104(6), 787-794 (1999). doi:10.1172/JCI7231

2. J. Levy, A.B. Atkinson, P.M. Bell, D.R. McCance, D.R. Hadden, Beta-cell deterioration determines the onset and rate of progression of secondary dietary failure in type 2 diabetes mellitus: the 10-year follow-up of the Belfast Diet Study. Diabet. Med. 15(4), 290-296 (1998). doi:10.1002/(SICI)1096-9136(199804)15: 4<290:AID-DIA570>3.0.CO;2-M

3. A.E. Butler, J. Janson, S. Bonner-Weir, R. Ritzel, R.A. Rizza, P.C. Butler, Beta-cell deficit and increased beta-cell apoptosis in humans with type 2 diabetes. Diabetes 52(1), 102-110 (2003)

4. J.J. Meier, R.C. Bonadonna, Role of reduced beta-cell mass versus impaired beta-cell function in the pathogenesis of type 2 diabetes. Diabet. Care 36(Suppl 2), S113-S119 (2013). doi:10. 2337/dcS13-2008

5. D.T. Finegood, L. Scaglia, S. Bonner-Weir, Dynamics of betacell mass in the growing rat pancreas. Estimation with a simple mathematical model. Diabetes 44(3), 249-256 (1995)

6. Y. Dor, J. Brown, O.I. Martinez, D.A. Melton, Adult pancreatic beta-cells are formed by self-duplication rather than stem-cell differentiation. Nature 429(6987), 41-46 (2004). doi:10.1038/ nature 02520

7. C. Talchai, S. Xuan, H.V. Lin, L. Sussel, D. Accili, Pancreatic beta cell dedifferentiation as a mechanism of diabetic beta cell failure. Cell 150(6), 1223-1234 (2012). doi:10.1016/j.cell.2012. 07.029

8. A. Ianus, G.G. Holz, N.D. Theise, M.A. Hussain, In vivo derivation of glucose-competent pancreatic endocrine cells from bone marrow without evidence of cell fusion. J. Clin. Investig. 111(6), 843-850 (2003). doi:10.1172/JCI16502

9. K. Terazono, H. Yamamoto, S. Takasawa, K. Shiga, Y. Yonemura, Y. Tochino, H. Okamoto, A novel gene activated in regenerating islets. J. Biol. Chem. 263(5), 2111-2114 (1988)

10. R. Graf, M. Schiesser, T. Reding, P. Appenzeller, L.K. Sun, F. Fortunato, A. Perren, D. Bimmler, Exocrine meets endocrine: pancreatic stone protein and regenerating protein-two sides of the same coin. J. Surg. Res. 133(2), 113-120 (2006). doi:10.1016/j. jss.2005.09.030 
11. T. Watanabe, Y. Yonemura, H. Yonekura, Y. Suzuki, H. Miyashita, K. Sugiyama, S. Moriizumi, M. Unno, O. Tanaka, H. Kondo et al., Pancreatic beta-cell replication and amelioration of surgical diabetes by Reg protein. Proc Natl Acad Sci USA 91(9), 3589-3592 (1994)

12. S. Rouquier, J.M. Verdier, J. Iovanna, J.C. Dagorn, D. Giorgi, Rat pancreatic stone protein messenger RNA. Abundant expression in mature exocrine cells, regulation by food content, and sequence identity with the endocrine reg transcript. J. Biol. Chem. 266(2), 786-791 (1991)

13. A.C. Nica, H. Ongen, J.C. Irminger, D. Bosco, T. Berney, S.E. Antonarakis, P.A. Halban, E.T. Dermitzakis, Cell-type, allelic, and genetic signatures in the human pancreatic beta cell transcriptome. Genome Res. 23(9), 1554-1562 (2013). doi:10.1101/ gr.150706.112

14. C. Bartoli, B. Gharib, D. Giorgi, A. Sansonetti, J.C. Dagorn, J.L. Berge-Lefranc, A gene homologous to the reg gene is expressed in the human pancreas. FEBS Lett. 327(3), 289-293 (1993)

15. C. Bonner, S. Bacon, C.G. Concannon, S.R. Rizvi, M. Baquie, A.M. Farrelly, S.M. Kilbride, H. Dussmann, M.W. Ward, C.M. Boulanger, C.B. Wollheim, R. Graf, M.M. Byrne, J.H. Prehn, INS-1 cells undergoing caspase-dependent apoptosis enhance the regenerative capacity of neighboring cells. Diabetes 59(11), 2799-2808 (2010). doi:10.2337/db09-1478
16. A. Kim, K. Miller, J. Jo, G. Kilimnik, P. Wojcik, M. Hara, Islet architecture: a comparative study. Islets 1(2), 129-136 (2009). doi:10.4161/isl.1.2.9480

17. J. Yang, L. Li, D. Raptis, X. Li, F. Li, B. Chen, J. He, R. Graf, Z. Sun, Pancreatic stone protein/regenerating protein (PSP/reg): a novel secreted protein up-regulated in type 2 diabetes mellitus. Endocrine (2014). doi:10.1007/s12020-014-0427-3

18. S. Bacon, M.P. Kyithar, J. Schmid, S.R. Rizvi, C. Bonner, R. Graf, J.H. Prehn, M.M. Byrne, Serum levels of pancreatic stone protein (PSP)/reg1A as an indicator of beta-cell apoptosis suggest an increased apoptosis rate in hepatocyte nuclear factor 1 alpha (HNF1A-MODY) carriers from the third decade of life onward. BMC Endocr. Disord. 12, 13 (2012). doi:10.1186/1472-6823-1213

19. A. El Ouaamari, D. Kawamori, E. Dirice, C.W. Liew, J.L. Shadrach, J. Hu, H. Katsuta, J. Hollister-Lock, W.J. Qian, A.J. Wagers, R.N. Kulkarni, Liver-derived systemic factors drive beta cell hyperplasia in insulin-resistant states. Cell Rep. 3(2), 401-410 (2013). doi:10.1016/j.celrep.2013.01.007

20. P. Yi, J.S. Park, D.A. Melton, Betatrophin: a hormone that controls pancreatic beta cell proliferation. Cell 153(4), 747-758 (2013). doi:10.1016/j.cell.2013.04.008 